\title{
A Mechanistic Model for Predicting and Optimising Oil-Sand Flow in Horizontal Wells
}

\author{
O. Bello' , G. Falcone' ${ }^{1}$, C. Teodoriv² and I. Udong' ${ }^{1}$ \\ 1 Department of Petroleum Engineering, 507 Richardson Building, 3116 TAMU, College Station, TX 77843-3116 - USA \\ 2 Institute of Petroleum Engineering, Agricolastrasse 10,38678 Clausthal-Zellerfeld - Germany \\ e-mail: oladele.bello@pe.tamu.edu - gioia.falcone@pe.tamu.edu - catalin.teodoriv@pe.tamu.edu - ime.udong@pe.tamu.edu
}

Résumé - Modèle mécanistique pour la prévision et l'optimisation des écoulements huile-sable dans des puits horizontaux - Les techniques de complétions intelligentes de puits avec gestion de venues de sable sont de plus en plus utilisées dans l'industrie pétrolière. Comparées aux techniques classiques de gestion de venues de sable, elles améliorent la productivité et la production cumulée d'hydrocarbures. Cependant, alors que les aspects géomécaniques de la production de sable sont de mieux en mieux appréhendés, la prévision et l'optimisation des écoulements diphasiques huile-sable dans les puits horizontaux posent toujours problème. Dans cette étude, une analyse théorique de l'écoulement d'un mélange huile-sable en suspension dans un puits horizontal a été effectuée. Pour ce faire, des modèles phénoménologiques ont été développés pour prédire la vitesse de remontée optimale ainsi que les profils de perte de charge, qui sont les deux paramètres clés pour optimiser la conception d'un puits horizontal dans un réservoir non consolidé. Le calcul de la perte de charge moyenne pour un écoulement diphasique huile-sable dans un puits horizontal est en accord avec les valeurs prédites par un modèle précédent, même pour des conditions d'opération variées. Cependant, le nouveau modèle évite de recourir à l'empirisme pour prévoir le comportement du puits dans le cas d'un écoulement multiphasique. Il peut également être appliqué à différentes géométries de puits. La méthode de calcul proposée a été testée sur une étude de cas hypothétique, afin de démontrer son applicabilité sur le terrain.

\begin{abstract}
A Mechanistic Model for Predicting and Optimising Oil-sand Flow in Horizontal Wells Smart well completion technology for sand management is being used more and more in the petroleum industry to increase productivity and cumulative hydrocarbon production over that of classical sand control techniques. While an understanding of the geomechanics aspects of sand production has begun to emerge, predicting and optimising two-phase oil-sand flow performance characteristics in horizontal wellbores remains a challenge. This theoretical study analysed two-phase, oil-sand suspended flow in a horizontal well by developing a new phenomenological model to predict lift velocity and pressure drop profiles, which are key parameters for designing optimal deployment of horizontal wells in an unconsolidated reservoir. Computations of average pressure drop for two-phase oil-sand flow in a horizontal well are in reasonable agreement with values predicted by a previous model for a relatively wide range of operating conditions. However, the new model eliminates the need for empiricism in predicting the wellbore hydraulics for oil-sand multiphase flow in horizontal wells and is applicable to different wellbore geometries. The proposed computational methodology has been applied to a hypothetical case study to demonstrate its field applicability.
\end{abstract}




\section{NOMENCLATURES}

$\Gamma_{m} \quad$ Mass transfer $\left(\mathrm{kg} / \mathrm{m}^{3} \mathrm{~s}\right)$

$\mu_{L} \quad$ Liquid viscosity (Pa.s)

$\rho_{L} \quad$ Liquid density $\left(\mathrm{kg} / \mathrm{m}^{3}\right)$

$\rho_{S} \quad$ Particle density $\left(\mathrm{kg} / \mathrm{m}^{3}\right)$

$\rho_{m} \quad$ Mixture density $\left(\mathrm{kg} / \mathrm{m}^{3}\right)$

$u_{L} \quad$ Liquid velocity $(\mathrm{m} / \mathrm{s})$

$u_{S} \quad$ Particle velocity $(\mathrm{m} / \mathrm{s})$

$u_{m} \quad$ Mixture velocity $(\mathrm{m} / \mathrm{s})$

$u_{C} \quad$ Critical velocity $(\mathrm{m} / \mathrm{s})$

$u_{\text {SLIP }}$ Slip velocity $(\mathrm{m} / \mathrm{s})$

$H_{L} \quad$ Liquid holdup

$H_{S} \quad$ Particle holdup

$d \quad$ Particle diameter (m)

$D \quad$ Pipe inner diameter (m)

$C_{D} \quad$ Drag coefficient

$N_{\operatorname{Re}, S}$ Particle Reynolds number

$N_{\mathrm{Re}, L}$ Liquid Reynolds number

$N_{\mathrm{Re}, m}$ Mixture Reynolds number

$\Psi \quad$ Particle shape factor

$\theta \quad$ Inclination angle (degree)

$f_{L} \quad$ Liquid-wall friction factor

$f_{S} \quad$ Solid-wall friction factor

$F_{L} \quad$ Force acting on liquid phase (N)

$F_{S} \quad$ Force acting on solid phase (N)

$p \quad$ Average pressure of mixture $(\mathrm{Pa})$

$M_{D} \quad$ Drag force per volume $(\mathrm{Pa} / \mathrm{m})$

$M_{W} \quad$ Wall frictional force/volume $(\mathrm{Pa} / \mathrm{m})$

$M_{s, S} \quad$ Particle-particle force/vol $(\mathrm{Pa} / \mathrm{m})$

$M_{G, m}$ Gravitational force/volume $(\mathrm{Pa} / \mathrm{m})$

$g \quad$ Acceleration due to gravity $\left(\mathrm{m} / \mathrm{s}^{2}\right)$

$V \quad$ Volume $\left(\mathrm{m}^{3}\right)$

\section{INTRODUCTION}

The need to increase recovery from producing hydrocarbon formations has seen major advances in smart well technology development. Horizontal wells can better control water coning in relatively thin oil columns, increase waterflooding efficiency, improve productivity and reservoir recovery in thin reservoirs, and reduce capital expenditure when compared to conventional field development methods. Many of the newly discovered fields with high recoverable reserves are situated in less accessible environments with unconsolidated formations (Gulf of Mexico, North Sea and Gulf of Guinea).

Conventional downhole sand completions (such as expandable sand screens, gravel packs, resin consolidation, frac and pack completions) strongly affect the overall well performance by introducing additional pressure drops (skin effects) and having higher installation and operating costs. As a result, sand management technology is getting more attention from the industry for its potential to increase reserve recovery, eliminate downhole sand exclusion systems, minimise problems associated with formation damage and impaired productivity, and reduce costs (Dusseault et al., 2001). The specific issues of the impact of sand production, ineffective sand transport, particle deposition and bed accumulation in horizontal and multi-lateral well sections are the prime focus of sand management technology. Impingement and deposition of sand particles in horizontal and multi-lateral wells results in erosion, corrosion, reduced wellbore flow capacity, unplanned well shut-down and increased downtime.

Several models have been proposed to incorporate frictional pressure drop effects on horizontal well drawdown and productivity index (Dikkens, 1990; Asheim et al., 1992; Sien et al., 1993; Cho and Shah, 2000; Guo, 2010). Two-phase frictional pressure drop has also been developed for gas-liquid (Ouyang, 1998) and liquid-liquid (Inikori and Wajtanowicz, 2002) flow conditions in horizontal wells. Extensive studies on particulate flows in horizontal pipes with settling and nonsettling systems have been published (Wicks, 1971; Doron et al., 1987; Matousek, 1997; Gillies et al., 1999; Kaushal and Tomita, 2005; Yang et al., 2006; Govier and Aziz, 2008), but few research works have been reported for oil-sand flow in horizontal wells.

Oil-sand flow occurs frequently in horizontal wells drilled in unconsolidated formations, even when sand management technology is implemented. The design of such horizontal wells depends on a detailed knowledge of oil-sand flow to predict wellbore hydraulic performance. Doan et al. (1996) used analytical and numerical modelling to investigate the transport of oil-sand flows with stationary sand bed loads in horizontal wells. The model considered a suspension of sand homogeneously dispersed in oil, where the particles are at least two diameters apart, flowing at isothermal conditions. This approach allows the particle-particle interactions to become negligible when compared to the interactions between the solid particles and the surrounding fluid. The oilsand suspension is treated as a continuum and the fluid phase as Newtonian. The numerical model also considered the important roles that viscosity and particle size play in the transport process.

Gillies et al. (1991) developed a correlation for hydraulic conveyance to predict pressure gradients in oil-sand pipe flows with sand bed loads. The predictions qualitatively agreed with the measured pressure drop. King et al. (2001) developed a model based on the traditional minimum transport velocity and pressure gradient, accounting for both boundary layer and viscous drag effects. The resulting equation provided the necessary pressure gradient required for transport, depending on whether the particle diameter is larger or smaller than the thickness of the viscous sub-layer. Almedeij and Algharaib (2005) developed a model for 
estimating the pressure gradient in horizontal, heterogeneous wellbore flow and presented two limiting velocities for preventing particle deposition and erosion in horizontal wells. The resulting model can be used to predict the pressure gradient in fully suspended oil-sand flow through horizontal wells.

Although some models have been used to analyse oil-sand flow in horizontal wells, there have not been any reported publications dealing with the impact of system, operating and geometric variables on pressure gradient and optimal transport velocity. This issue needs to be well understood in order to quantify the impact of oil-sand flow on wellbore pressure profiles and the estimation of horizontal wells productivity. Therefore, the objective of this present work is to develop a general mechanistic model and computer programme to study the effects of various parameters on pressure characteristics in horizontal wells with oil-sand flow so as to optimise the wells design. The proposed equations in the new model incorporate key physics of oil-sand flows and also predict optimal transport velocity for preventing flow assurance problems associated with sand particle transport in horizontal wells.

\section{MODEL DEVELOPMENT}

This section presents a theoretical analysis of oil-sand flow through a horizontal well system under heterogeneous flow conditions. The proposed phenomenological model involves balance equations deduced from macroscopic mass and momentum conservation laws. It uses maximising functions to obtain the optimal transport velocity that minimises pressure drop. The computational method is also capable of determining the best option that meets various design, system and operating constraints.

\subsection{Assumptions}

The theoretical analysis and mathematical model for oil-sand flow in horizontal wells is developed under the following assumptions:

- the flow is one-dimensional, fully developed, steady-state and isothermal;

- the oil-sand mixture is assumed to behave as a Newtonian fluid;

- both the liquid and solid phases are incompressible;

- the flow field is governed mainly by body and interaction forces between the two flowing phases;

- acceleration effects are negligible in the absence of interfacial mass transfer between the phases;

- the radial and tangential components of the velocity vector are assumed to be negligible;

- the influence of solid particle motion on the continuous phase is not accounted for in the developed model;

- the effects of flow distribution and large-scale fluctuations are neglected;
- no interaction between fine-fine and coarse-coarse particles is assumed. However, fine and coarse particles do interact;

- the pressures in all phases are the same within a given computational cell.

\subsection{Formulation of the Governing Equations}

The oil-sand mixture mass and momentum conservation equations are given as:

$$
\begin{gathered}
\frac{\partial\left(\rho_{m}\right)}{\partial t}+\frac{\partial\left(\rho_{m} u_{m}\right)}{\partial x}=\Gamma_{m} \\
\frac{\partial\left(\rho_{m} u_{m}\right)}{\partial t}+u_{m} \frac{\partial\left(\rho_{m} u_{m}\right)}{\partial x}=-\left(M_{k}+\frac{\partial p}{\partial x}\right)
\end{gathered}
$$

where:

$$
M_{k}=M_{D}+M_{W}+M_{s, s}+M_{G, m}+M_{T M}
$$

The left-hand side of Equation (1) describes the internal change of mass with time and the convective flux crossing the boundaries of the control volume. The term on the righthand side describes the mass transfer between the phases. The terms on the right-hand side of Equation (2) denote the body forces and momentum transfer terms, and can generally be described as the force per volume acting on the mixture element in the control volume. These are the overall pressure gradient, the gravitational forces, wall-particle interaction forces, particle-particle interaction forces, inter-phase momentum (drag) forces, liquid-wall interaction forces, and turbulent dispersive forces. In this investigation, the virtual mass and Saffman's lift forces are assumed negligible and ignored. $\rho_{m}$ is the density of the mixture and $u_{m}$ is the velocity of the mixture. $\partial t$ and $\partial x$ represent the partial derivatives against time and axial distance, respectively. Under the assumption of steady-state and zero mass transfer between the phases, the governing equations reduce to:

$$
-\frac{d p}{d x}=M_{D}+M_{W}+M_{s, s}+M_{G, m}+M_{T M}
$$

\subsection{Decomposition of Forces per Unit Volume}

The force per volume $\left(M_{k}\right)$ expressions are given as follows:

\subsubsection{Pressure Force per Unit Volume}

For the pressure forces, the force acting on the surface of the phase can be seen as:

$$
\begin{gathered}
P_{P}=p \partial y \partial z-\left(p+\frac{\partial p}{\partial x} \partial x\right) \partial y \partial z \\
P_{P}=-\frac{\partial p}{\partial x} d x d y d z
\end{gathered}
$$


When both sides of the equation are divided by the total volume, the force per volume is obtained. Notice that the volumetric fraction appears, since total pressure acts on all the surfaces, independent of the phase:

$$
F_{P L}=\frac{p_{\mathrm{p}}}{V}=-H_{L} \frac{\partial p}{\partial x}
$$

for the case of the liquid phase, or:

$$
F_{P S}=\frac{p_{p}}{V}=-H_{S} \frac{\partial p}{\partial x}
$$

for the case of the solid phase.

Assuming equal pressure gradient for the phases in a given cross-section of the flow conduit, Equations (6) and (7) reduce to:

$$
F_{P L}+F_{P S}=-\left(H_{L}+H_{S}\right) \frac{\partial p}{\partial x}=-\frac{\partial p}{\partial x}
$$

\subsubsection{Drag Force per Unit Volume}

The drag force depends on the pressure distribution acting on the surface of a material immersed in the liquid phase and the interfacial friction owing to the slip between phases. For the mixture, the drag force can be describe as follows:

$$
\begin{gathered}
M_{D}=\beta\left(u_{L}-u_{S}\right)=\beta\left(u_{S L I P}\right) \\
\beta=\frac{3}{4} C_{D} \frac{H_{S} \rho_{S}}{d} u_{S L I P}\left(H_{s}\right)^{-2.65} \\
N_{\mathrm{Re}, S}=\frac{\rho_{L} u_{S L I P} d}{\mu_{L}} \\
u_{S L I P}=u_{L}-u_{S}=\frac{u_{S L}}{1-H_{S}}-\frac{u_{S S}}{H_{S}}
\end{gathered}
$$

The Danielson (2007) equation was used to predict sand holdup and is given as follows:

$$
\begin{array}{r}
u_{C} H_{S}^{2}+\left(u_{S L}+u_{S S}-u_{C}\right) H_{S}-u_{S S}=0 \\
u_{C}=K\left(\frac{\mu_{L}}{\rho_{L}}\right)^{-1 / 9} d^{1 / 9}\left[g D\left(\frac{\rho_{S}-\rho_{L}}{\rho_{L}}\right)\right]^{5 / 9}
\end{array}
$$

The $C_{D}$, is estimated using the drag coefficient correlation developed by Swamee and Ojha (1991) for particles in incompressible fluids based on the Corey shape factor $(\Psi)$. The Swamee and Ojha (1991) correlation is given as follows:

$$
\begin{aligned}
& C_{D}=\frac{48.5}{\left(1+4.5 \Psi^{0.35}\right)^{0.8} N_{\mathrm{Re}, S}^{0.64}}+ \\
& \left(\frac{N_{\mathrm{Re}, S}}{N_{\mathrm{Re}, S}+100+100 \Psi}\right)^{0.32}\left(\frac{1}{\Psi^{18}+1.05 \Psi^{0.8}}\right)
\end{aligned}
$$

The equation is applicable in the range:

$$
0.3<\Psi<1 \text { and } 1<N_{\mathrm{Re}, S}<10000
$$

The equivalent particle diameter for the mixture of particles of different sizes is defined as:

$$
d=\frac{\sum_{i=1}^{n} f_{i} d_{i}}{\sum_{i=1}^{n} f_{i}}
$$

where $f_{i}$ is defined as the frequency of $i$ particles of diameter $d_{i}$.

\subsubsection{Wall Frictional Force per Volume}

In this model, friction occurs due to the interfacial friction between the mixture and the inner wall of pipe. The total pressure drop caused by friction can be expressed as:

$$
M_{W}=\frac{2 \rho_{m} u_{m}^{2}}{D}\left(f_{L}+f_{s s} \cos (\theta)\right)
$$

where $\theta$ is the inclination angle of the well. $f_{L}$ is the liquid friction factor in the horizontal well; it is evaluated using the Seines et al. (1993) equation:

$$
\begin{gathered}
f_{L}=\frac{64}{N_{\mathrm{Re}, L}} \quad\left(\text { for } N_{\mathrm{Re}, L}<2000\right) \\
f_{L}=\frac{1}{\left[1.8 \log _{10}\left(\frac{6.9}{N_{\mathrm{Re}, L}}+\left(\frac{\varepsilon}{3.7 D}\right)^{10 / 9}\right)\right]^{2}} \\
\left(\text { for } N_{\mathrm{Re}, L}>4000\right) \\
N_{\mathrm{Re}, L}=\frac{u_{S L} D \rho_{L}}{\mu_{L}}
\end{gathered}
$$

For, $2000<N_{R e, L}<40000, f_{L}$ can be obtained by interpolating between friction factors computed at $N_{R e, L}=2000$ and $N_{R e, L}=4000 . f_{S S}$ is evaluated using the Doron et al. (1987) equation below:

$$
f_{S S}=\frac{0.046}{N_{\mathrm{Re}, m}^{0.2}}
$$

The Reynolds number for this relation is given by:

$$
N_{\mathrm{Re}, m}=\frac{\rho_{m} V_{m} d}{\mu_{L}}
$$

where $\rho_{m}$ is the mixture density and it is defined as:

$$
\rho_{m}=\rho_{S} \mathrm{H}_{S}+\rho_{L}\left(1-\mathrm{H}_{S}\right)
$$

$u_{m}$ is the mixture velocity and it is defined as:

$$
u_{m}=\frac{4}{\pi D^{2}}\left[\frac{\rho_{L} q_{L}+q_{S} \rho_{S}}{\rho_{m}}\right]
$$

where $q_{L}$ is the liquid rate and $q_{S}$ the solid rate 


\subsubsection{Particle-particle Interaction Force per Volume}

The particle-particle interaction force $\left(M_{S, S}\right)$ per volume in liquid-solid two-phase pipe flow can be written as follows:

$$
M_{s, s}=d^{2} \frac{q_{S} \rho_{S}}{D^{2}} \frac{u_{S L}}{\left(\frac{\pi D^{3}}{6}\right)}
$$

\subsubsection{Gravity Force per Unit Volume}

The gravity force $\left(M_{G, m}\right)$ per volume in liquid-solid twophase pipe flow can be written as follows:

$$
M_{G, m}=\rho_{m} \mathrm{~g} \sin \theta
$$

This force only appears in consideration of a vertical well. It will have negligible impact in the case of a horizontal well.

\subsubsection{Particle-liquid Dispersive Force per Unit Volume}

The particle-liquid turbulent interaction force $\left(M_{T M}\right)$ per volume in liquid-solid two-phase flow can be written as follows (Davies, 1987):

$$
M_{T M}=\frac{\rho_{M}}{\left(\frac{\pi D^{3}}{6}\right)} \frac{\pi}{4}\left(d_{S}\right)^{2} \quad\left(u^{\prime}\right)^{2}
$$

where $u^{\prime}$ is the turbulent fluctuation velocity. The $\mu_{L}$ and $\rho_{L}$ are the liquid dynamic viscosity and density, respectively. $d$ and $D$ are the sand particle equivalents and pipe diameters, respectively. Davies (1987) proposed a model for estimating the eddy fluctuation force (or the force of the turbulent eddies) acting on asymmetric fully suspended solid particle in liquid/solid two-phase pipe flow with the turbulent fluctuation velocity defined by:

$$
u^{\prime}=(0.16)^{1 / 3}\left(\frac{\mu_{L}}{\rho_{L}}\right)^{1 / 12} u_{\min }^{0.92} d^{1 / 3} D^{-0.42}
$$

The $u_{\min }$ is the minimum mean flow velocity required to suspend sand particles and can be calculated as follows:

$$
\begin{aligned}
& u_{\min }=1.08\left(1+\alpha H_{S}\right)^{1.09}\left(1-H_{S}\right)^{0.55 n} \\
& \times\left(\frac{\mu_{L}}{\rho_{L}}\right)^{-0.09} d^{0.18}\left[2 g \frac{\rho_{S}-\rho_{L}}{\rho_{L}}\right]^{0.54} D^{0.46}
\end{aligned}
$$

where $\alpha$ is a constant given by Davies (1987) to be 3.64. $n$ is a constant which accounts for hindered settling. $n$ is about 4 when $1<N_{\operatorname{Re}, S}<10$ and falls to 3 when $N_{\operatorname{Re}, S}=100 . H_{S}$ is the local input volume fraction of solid particles, which is calculated using the Danielson (2007) method.

\subsection{Computational and Optimisation Algorithm}

The MATLAB ${ }^{\circledR}$ environment was used to develop the computational program for predicting and optimising hydraulic performance of oil-sand flow in a horizontal well. The procedure for the computational workflow incorporating the "golden search" approach, which is an unconstrained minimisation method used in this study (Rao, 1996), is shown in Figure 1. The study used an objective function to predict the minimum total pressure drop per unit length in the horizontal oil-sand production well for given system, operating and geometric conditions. The objective function was constrained by imposing a limiting deposition velocity in order to narrow the search domain of the optimisation and so reduce processing time and enhance convergence. The "golden search" optimisation method is formulated such that the iteration scheme within the loop stops when the system reaches the minimum pressure drop. The oil flow rate that corresponds to the minimum pressure drop is declared as corresponding to the optimal transport velocity. Otherwise, the initial value for the optimal transport velocity is adjusted and the iteration process is repeated. A modification of the method proposed by Cho and Shah (2000) is used to calculate the pressure profiles.

The step-by-step computational procedures for solving the governing equations and estimating the optimal transport velocity in the horizontal wellbore are as follows:

- select the flow geometry;

- provide an initial estimate the value of $V_{\text {OPTIMAL }}$;

- segment the flow conduit into different computational cells (length increments);

- assign entry values (initial system, operating and geometric parameters) to the first computational cell;

- calculate the equivalent sand particle diameter;

- determine the sand particle hold-up and specific twophase flow parameters at the outlet of the computational cell;

- solve the governing equations and calculate the total pressure drop;

- estimate the outlet pressure for the first computational cell using the calculated total pressure drop, $\Delta p_{i}$, in the first computational cell;

- repeat steps [4 to 8] for the remaining fragments of the horizontal well until the total length is covered;

- on reaching the end of the horizontal well length, compare the previously calculated pressure drops to ascertain whether the minimum pressure drop has been attained within the preset minimum and maximum velocities;

- if the value calculated in step [10] is not the minimum pressure drop, then a new estimate is made for $V_{\text {OPTIMAL }}$ and the calculation procedure begins again at step [2]. This cycle of calculation is repeated until the minimum pressure drop has been achieved.

If a minimum pressure drop has been attained, create an output of the predicted optimal liquid velocity and the corresponding minimum pressure drop and stop the calculation cycle. 


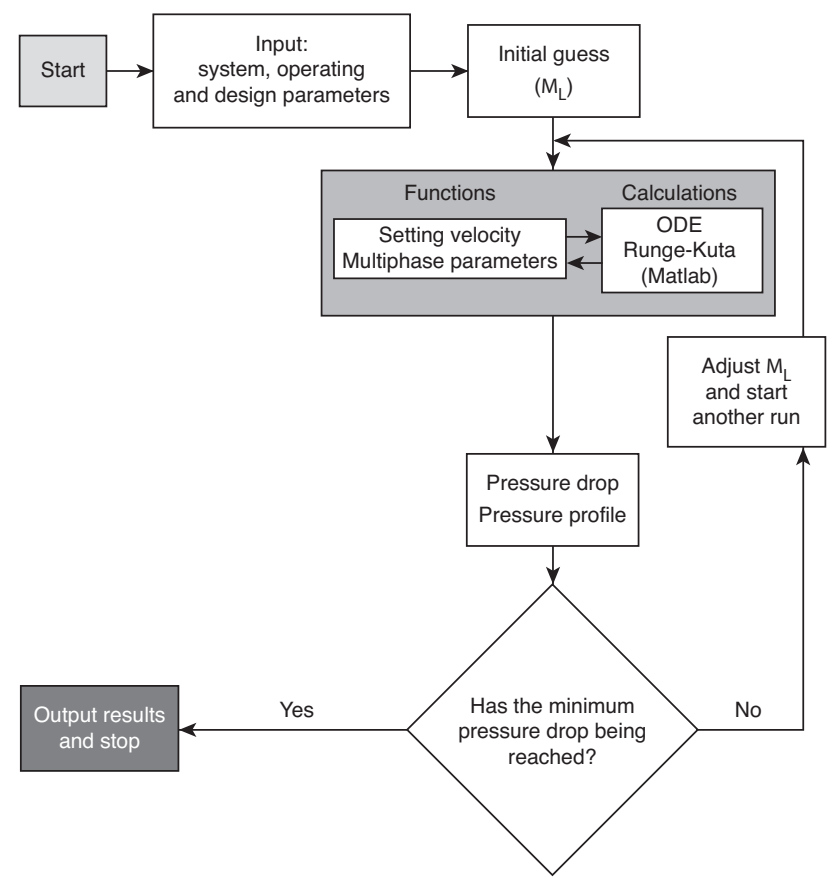

Figure 1

Flow chart of computation and optimisation method presented in this study.

\section{RESULTS AND DISCUSSION}

\subsection{Model Validation and Field Application}

Mathematical models must be validated prior to actual use, either by comparison of the developed model with data obtained from field-scale experiments, or by comparison of the model with the output from other published or existing models that have been confirmed to be reliable, or both. The hydraulic model for horizontal oil-sand flow in horizontal wells published by Almedeij and Algharaib (2005) was chosen as the validation method in this study. The parameters used for simulating the hypothetical case study case scenario are given in Table 1.

As shown in Figures 2 and 3, the pressure gradient increases with increasing bulk flow velocities. The average relative percentage error for the pressure gradient values predicted by the two models is less than $10 \%$ when the flow velocity is changed from 1 to $3 \mathrm{~m} / \mathrm{s}$. The difference in the predicted pressure gradient values can be attributable to inability of the Almedeij and Algharaib (2005) model to adequately account for hydrodynamic processes controlling pressure drop characteristics in oil-sand flow in horizontal wells. The new model, representing a mechanistic approach, has a wider range of applicability than the simplified empirical model. It is also does not contained any empirical parameters and tuning. The discrepancy in predicted results of
TABLE 1

Parameters used in the model validation and application study

\begin{tabular}{l|c}
\hline Variables & Base case value \\
\hline In-situ oil rate $\left(\mathrm{m}^{3} / \mathrm{s}\right)$ & 0.0105 \\
\hline Sand loading rate $\left(\mathrm{m}^{3} / \mathrm{s}\right)$ & 0.00021 \\
\hline Pressure drawdown $($ bar $)$ & 10.34 \\
\hline Wellbore orientation & Horizontal \\
\hline Tubing internal diameter $(\mathrm{m})$ & 0.114 \\
\hline Wellbore lateral length $(\mathrm{m})$ & 1220 \\
\hline Effective wall roughness $(\mathrm{m})$ & 0.001 \\
\hline Inlet pressure $($ bar $)$ & 389.66 \\
\hline Oil density $\left(\mathrm{kg} / \mathrm{m}^{3}\right)$ & 820 \\
\hline Oil viscosity $(\mathrm{Pa} . \mathrm{s})$ & 0.001 \\
\hline Sand grain size $(\mathrm{m})$ & 0.0003 \\
\hline Sand grain density $\left(\mathrm{kg} / \mathrm{m}^{3}\right)$ & 2500 \\
\hline Sand grain shape factor & 0.910 \\
\hline
\end{tabular}

pressure gradient can lead to a significant over-estimation of horizontal well performance.

\subsection{Parametric Studies}

One of the variables that operators have some control over is the oil rate flowing through a well and hence it is pertinent to examine the synergy effects of this parameter and other system, design and operating variables on pressure loss in the horizontal wellbore. Figure 4 shows the pressure drop distributions along the well's axial direction at different oil flow rates and for various well diameters. It can be observed that, as the liquid velocity increases for a fixed wellbore diameter, the pressure drop increases more significantly at low wellbore than at high diameter. An increase in the wellbore diameter decreases the pressure drop. A decreasing wellbore diameter will decrease the available flowing area, which in turn will increase both the velocity and pressure drop due to friction. It is interesting to note how high the pressure drop can become with only a slight decrease in diameter of about $0.11 \mathrm{~m}$. Figure 4 clearly shows that an increase in diameter can significantly minimise pressure losses along the horizontal wellbore and that a minimum value of the pressure drop exists where the liquid velocity increases for a fixed wellbore diameter. For a liquid velocity greater than $0.5 \mathrm{~m} / \mathrm{s}$, the curve goes through this minimum point and skews as the liquid velocity increases. The optimal liquid velocity is that corresponding to the minimum pressure losses in the horizontal wellbore.

Figure 5 shows the trend in pressure drop as a function of liquid velocity and wellbore roughness. The pressure drop relatively increases as the liquid velocity increases for a fixed 


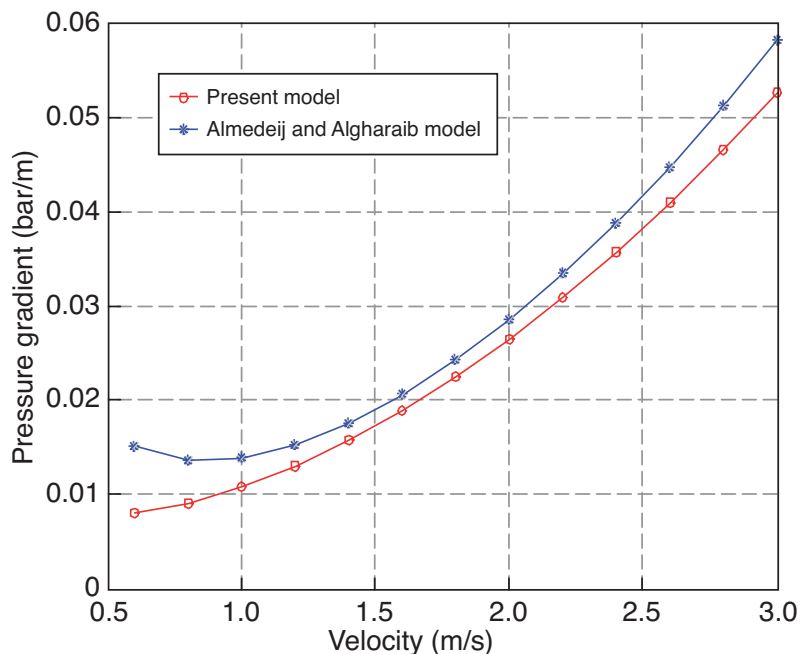

Figure 2

Pressure drop $v s$ velocity for base case of the new model and the Almedeij and Algharaib (2005) model.

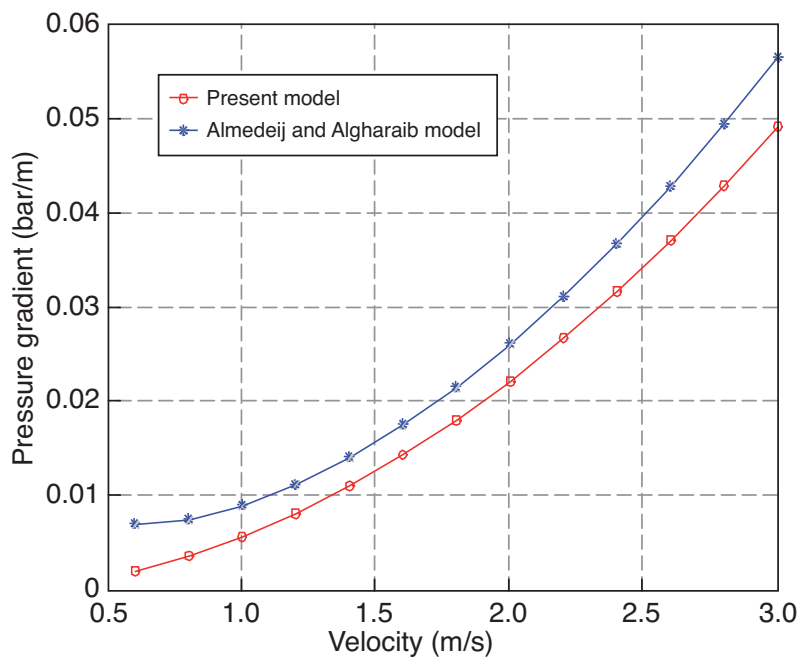

Figure 3

Pressure drop $v s$ velocity for the base case of a mixture of $50 \%$ medium-sized $(0.0003 \mathrm{~m})$ and $50 \%$ fine-sized $(0.00009 \mathrm{~m})$ particles for the new model and the Almedeij and Algharaib (2005) model.

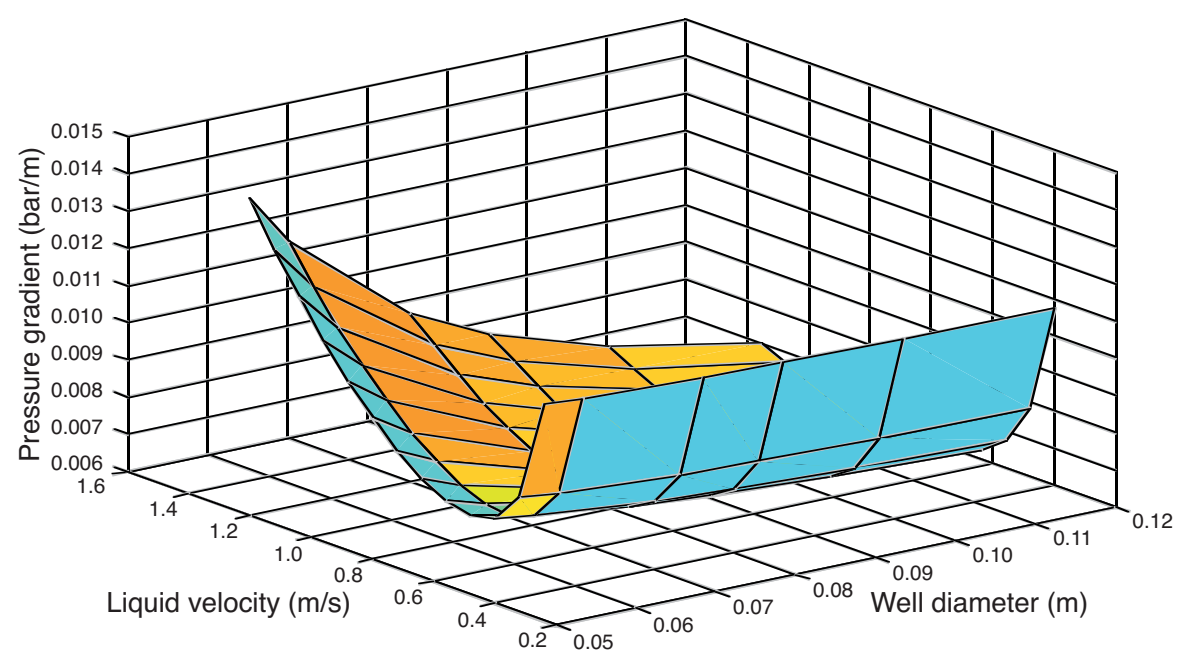

Figure 4

Variation of pressure gradient with liquid velocity for different values of pipe diameters.

wellbore roughness, but it is rather independent of the latter at low liquid velocity. The magnitude of pressure drop increases as the liquid velocity increases from $0.6 \mathrm{~m} / \mathrm{s}$ to $1.5 \mathrm{~m} / \mathrm{s}$, which indicates that the influence of liquid velocity on pressure drop is most pronounced at highest wellbore roughness for the ranges of values investigated. The effect of wellbore roughness on the pressure drop depends more strongly on the flow rate than on the change of roughness itself. However, there is a clear tendency for pressure drop to increase for the higher values of the wellbore roughness. Figures 6 to 8 show the effects of oil flow rate on pressure drop as a function of sand particle density, liquid density, and sand particle size distributions, respectively. The produced sand particles have different physical characteristics that are pertinent to study particle density effects on pressure drops. Figure 6 shows a significant effect of sand particle density for low and high liquid velocities. Higher particle density means higher mixture density, which leads to higher pressure 
Figure 5

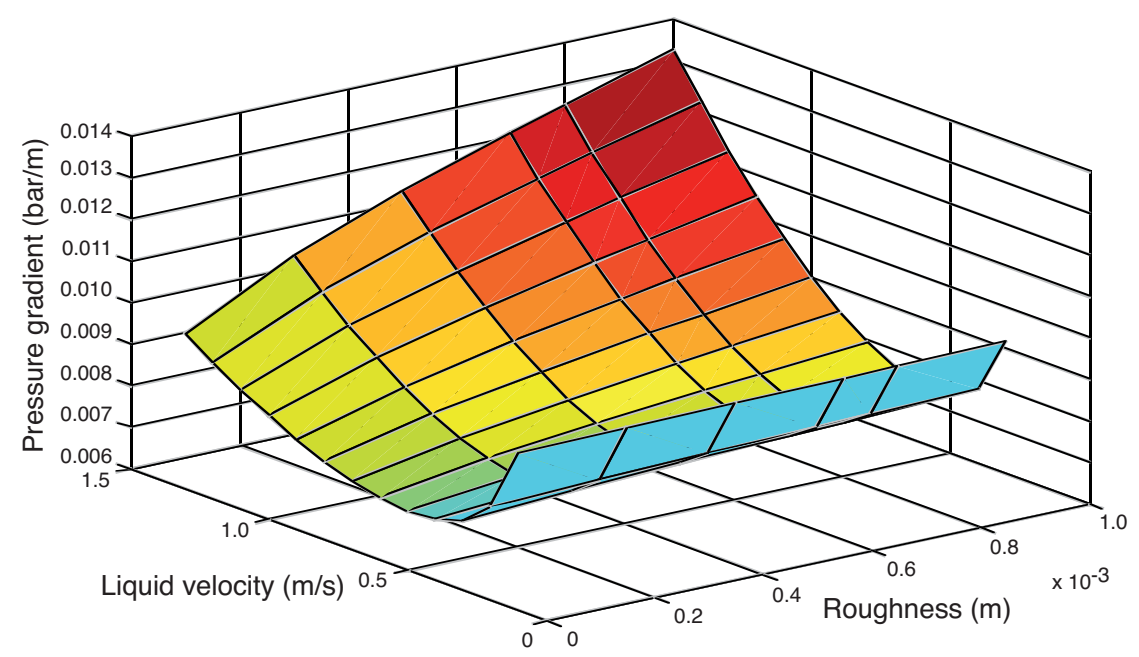

Variation of pressure drop with liquid velocity for different values of wellbore roughness.

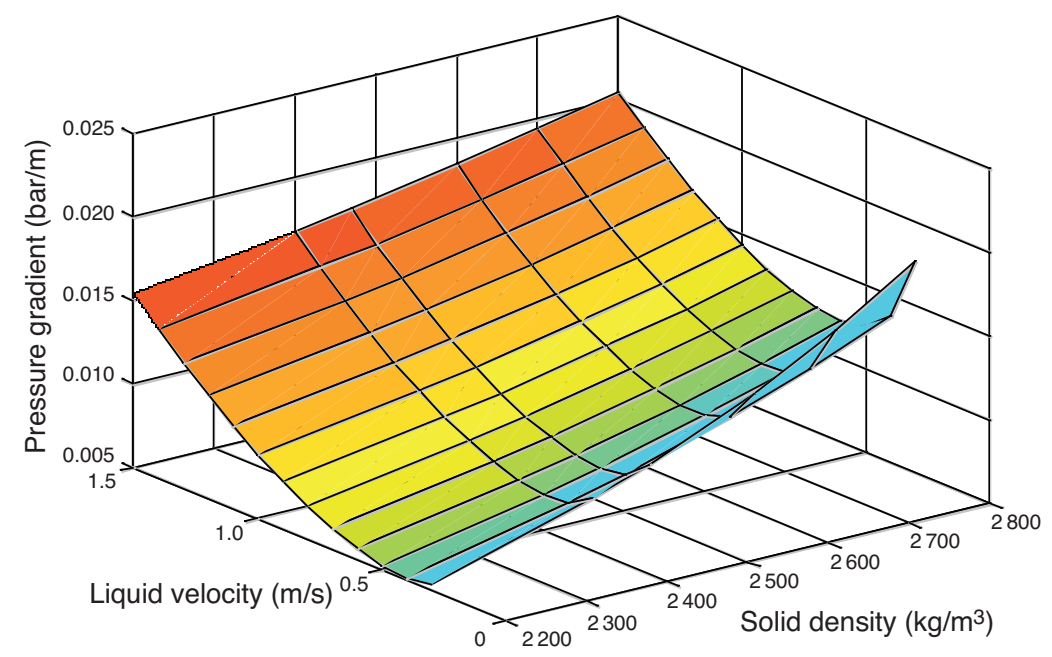

Figure 6

Variation of pressure drop with liquid velocity for different values of particle density.

drop. Figure 7 compares the pressure gradients for various liquid velocities and densities. In general, the pressure drop increases as either liquid velocity or liquid density increases, but the effect of liquid density is not very pronounced. Figure 8 shows that the effect of fine- and medium-sized sand particles on pressure gradient is relatively small at low particle loading rates. However, the highest values of coarse particles (equivalent grain size of $0.0006000 \mathrm{~m}$ for $50 \%$ coarse $+50 \%$ medium) result in the greatest pressure gradient at the same low sand-loading rate. This trend means that a bigger sand particle size will increase the pressure gradient along the horizontal wellbore length as the dilute liquid-solid flow system is dominated by interfacial momentum transfer and frictional drag forces. This also influences both sand particle-particle interactions and sand particle-wellbore wall frictional loss. A relative increase in pressure drop exists as the liquid velocity increases for a fixed equivalent sand grain size distribution of $0.00009 \mathrm{~m}$ (100\% fines), $0.0002871 \mathrm{~m}$ ( $1 \%$ coarse $+90 \%$ medium $+9 \%$ fines), $0.0003 \mathrm{~m}$ ( $100 \%$ medium), $0.0003090 \mathrm{~m}$ $(5 \%$ coarse $+85 \%$ medium $+10 \%$ fines $)$, and $0.0003495 \mathrm{~m}$ $(10 \%$ coarse $+85 \%$ medium $+5 \%$ fines $)$, respectively. The effects of the fines and medium sand particle sizes on the pressure drop are quite small, but the pressure drop magnitude jumps to maximum when the coarse sand particle size fraction increases by 50\%. This effect can be explained on the basis of the relatively large coarse sand particle surface 


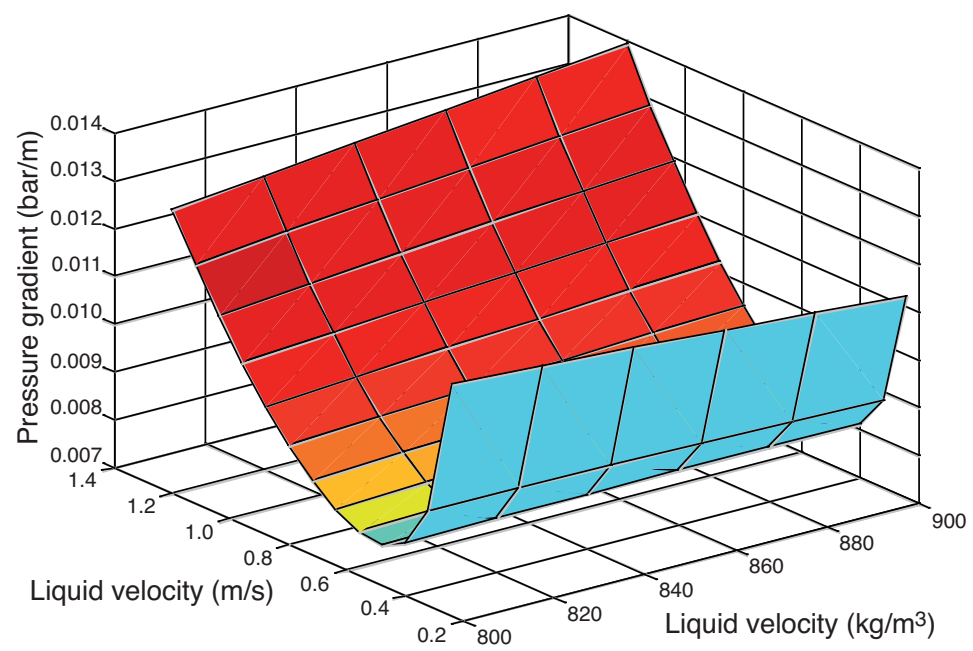

Figure 7

Variation of pressure drop with liquid velocity for different values of liquid density.

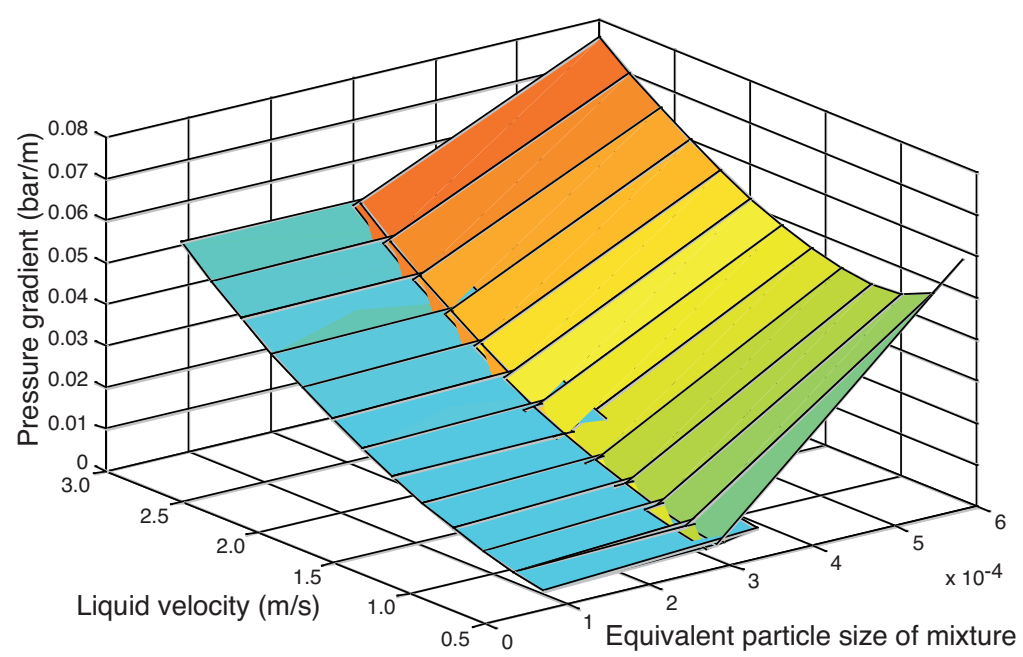

Figure 8

Variation of pressure drop with liquid velocity for different values of sand mixture grain size.

area and the momentum that is transferred in form of a drag force. The larger the surface area, the greater the energy loss in the horizontal wellbore.

\subsection{Horizontal Wellbore Pressure Profiles}

The predicted wellbore pressure profiles obtained for the base case using the proposed mechanistic model and that by the Almedeij and Algharaib (2005) are compared in Figure 9. Only slight differences between the models can be observed. Figures 10 to 11 show the effect of sand grain size and sand particle loading rates on the pressure profiles for the proposed model. In Figure 10, the pressure profiles for the different sand grain sizes are presented and show that the effect of particle diameter on pressure profiles in the wellbore can be very significant with increasing sand particle size. The observed relationship agrees with field experience. A bigger particle size will increase the pressure drop across the wellbore length because the liquid-solid system is dominated by interfacial frictional drag forces, particulate slurry flowwellbore wall interactions, particle-particle collisions and dispersive forces. The drag force is inversely proportional to the particle diameter and directly proportional to the slip velocity. Comparing the different sand particle size values used in this study reveals that the decrease in the wellbore pressure profile is more rapid for bigger particles. A similar 


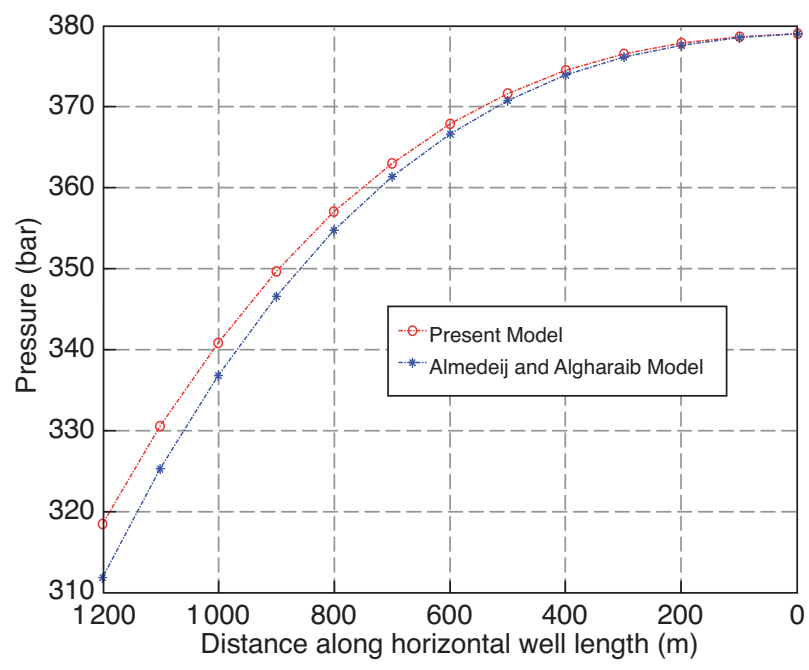

Figure 9

Horizontal wellbore pressure profiles for the two models $(d s$ $=0.0001 \mathrm{~m})$.

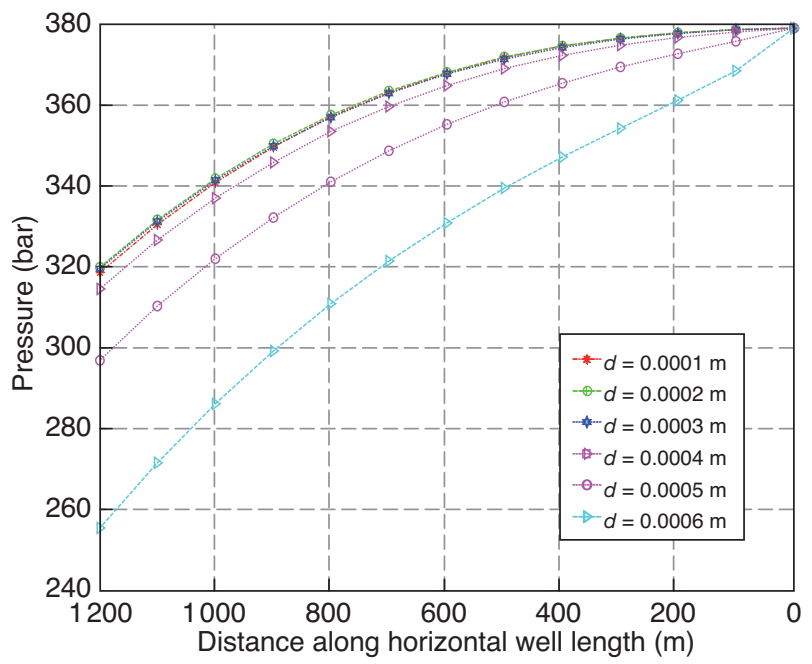

Figure 10

Horizontal wellbore pressure profiles for different sand grain sizes - proposed model.

trend is also observed for the sand particle loading rate effects on the wellbore pressure profiles in Figure 11. The significant drop in the wellbore pressure profile as sand is produced has a significant impact on wellbore productivity arising from excessive drawdown across the producing zone. The high drawdown also increases the water coning and matrix failure, causing episodic increases in sand influx based on increasing hydrodynamic forces that initiate more destabilisation and fluidisation of the intact formation.

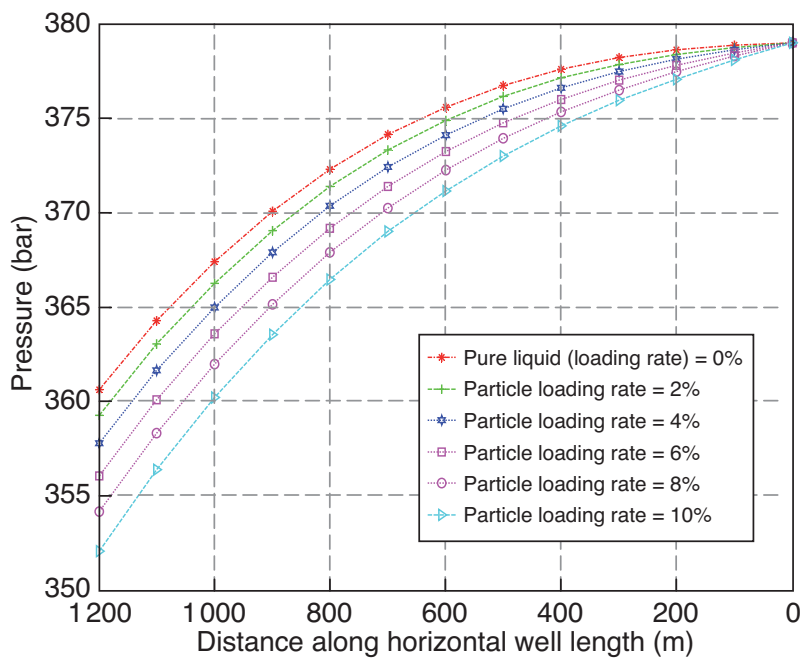

Figure 11

Horizontal wellbore pressure profiles for different particle loading rates $(d s=0.0003 \mathrm{~m})$ - proposed model.

\section{CONCLUSIONS}

- A simple mechanistic model for analysing and predicting the performance of oil-sand flow in horizontal well is developed;

- A comparative test with a published semi-empirical model indicates that the proposed phenomenological/ modelling approach is sufficiently accurate for engineering applications;

- The mechanistic model presented in this study eliminates the need for empiricism and parameter tuning. The model is also not confined to the limits imposed on the range of applicability of the semi-empirical correlation;

- The computational algorithm provides a systematic approach in predicting pressure gradient and optimal transport velocity to prevent sand deposition and accumulation in horizontal oil wells;

- The results provide some insight into the flowing pressure profiles in horizontal wells with oil-sand flow. The effects of sand production on wellbore pressure profiles could have high impact on the estimation of horizontal well productivity. More so, excessive pressure loss in horizontal wells will promote water coning problem;

- The methodology may be used to lower costs by identifying optimum operating conditions that minimise flow assurance problems, downtime and significant workover requirements for oil-sand flows in horizontal wells under different constraints;

- The proposed model can help production engineers to compare performance profiles for various alternatives and improve design guidelines; 
- Further studies on transient oil-sand flow are required to extend the range of investigation on oil-sand flow in horizontal wells.

\section{REFERENCES}

1 Almedeij J.H., Algharaib M.K. (2005) Influence of sand production on pressure drawdown in horizontal wells: theoretical evidence, J. Petrol. Sci. Eng. 47, 137-145.

2 Bratli R.K., Dusseault M.B., Santarelli F.J., Tronvoll J. (2000) Sand management protocol increases production rate, reduces completion costs, Proc. Trinidad and Tobago Biennial SPE Conf., Port-of-Spain.

3 Cho H., Shah S.N. (2000) Optimization of Well Length for Horizontal Drilling, J. Can. Petrol. Technol., Calgary, Alberta.

4 Davies J.T. (1987) Calculation of critical velocities to maintain solids suspension in horizontal pipes, Chem. Eng. Sci. 42, 7, 1667-1670.

5 Danielson T.J. (2007) Sand transport in multiphase pipelines, Proceedings of the Offshore Technology Conference, Houston, USA, OTC 18691.

6 Doan Q., Farouq Ali S.M., George A.E., Oguztoreli M. (1996) Simulation of sand transport in a horizontal well, Proceedings of International Conf. on Horizontal Well Technology, Calgary, Alberta, November 16-20. SPE 37106.

7 Doron P., Garnica D., Barnea D. (1987) Slurry Flow in Horizontal Pipes: Experimental and Modeling, Int. J. Multiphas. Flow 13, 4, 535-547.

8 Dusseault M.B., Tronvolli J., Santilippo F., Santarelli F.J. (2000) Sand-self cleaning in high rate oil wells using sand management, Int. Conf. on Formation Damage, SPE 58786.

9 Gillies R.G., Hill K.B., Mckibben M.J., Shook C. (1999) Solids transport by laminar Newtonian flows, Powder Technol. 104, 269-277.

10 Govier G.W., Aziz K. (2008) The Flow of Complex Mixtures in Pipes, Second Edition, Society of Petroleum Engineer.

11 Guo B. (2010) Corrections to horizontal drain hole productivity equations for wellbore friction effect, J. Petrol. Sci. Eng. 70, 344-349.

12 Inikori O.O., Wajtanowicz A.K. (2002) Effect of two-phase oilwater flow and frictional pressure loss in the wellbore on water cresting in horizontal wells. ETCE 2002/Prod. 29165, 25th ASME Annual Engineering Technology Conference on Energy, Houston, TX, February 4-5.
13 Kaushal D.R., Sato K., Toyota T., Funatsu K., Tomita Y. (2005) Effect of particle size distribution on pressure drop and concentration profile in pipeline flow of highly concentrated slurry, Int. J. Multiphas. Flow 31, 809-823.

14 King M.J.J., Fairhurst C.P., Hill T.J. (2001) Solids transport in multiphase flows: applications to high viscosity systems, $J$. Energ. Resour. 123, 200-204, September.

15 Matousek V. (1997) Flow mechanism of sand-water mixtures in pipelines, PhD Thesis, Technical University of Delft, Delft, Netherlands.

16 Ouyang L.-B. (1998) Single phase and multiphase fluid flow in a wellbore, PhD Dissertation, Stanford University, Stanford, California.

17 Rao S.S. (1996) Engineering Optimization, John Wiley and Sons, Inc.

18 Seines K., Aavatsmark I., Lien S.C., Rushworth P. (1993) Consider wellbore friction effects in planning horizontal wells, $J$. Petrol.Technol. October, 994-1000.

19 Shook C.A., Gillies R.G., Kristoff B.J., Small M.H. (1991) Sand transport mechanism in horizontal wells, Proceedings of the 4th Sask. Pet. Conf., Regina, Paper \# 15.

20 Swamee P.K., Ojha C.S.P. (1991) Drag coefficient and fall velocity of non-spherical particles, J. Hydraul. Eng. - ASCE 117, 660-667.

21 Tronvoll J., Dusseault M. Sanfilippo F., Santarelli F.J. (2001) The Tools of Sand Management 2001 Annual Technical Conference and Exhibition, New Orleans, Louisiana, Sept. 30-Oct 3.

22 Wicks M. (1971) Transport of solids at low concentration in horizontal pipes, Advances in Solid-Liquid Flow in Pipes \& Its Application, Zandi I. (ed.), Pergamon Press, pp. 101-124.

23 Yang Z.L., Laux H., Ladam Y., Danielson T.J., Leporcher E., Martins A.L. (2006) Dynamic Simulation of Sand Transport in Pipelines. Proceedings of the 5th BHR North American Conference on Multiphase Technology, Banff, Canada, May 31June 2, 2006.
Final manuscript received in June 2010 Published online in May 2011 